\title{
Numerical Simulation of Natural Convection in a Rectangular Cavity with Heated Triangle and Internal Heat Generation
}

\author{
Md. Shirazul Hoque Mollah ${ }^{1}$, Md. Shahidul Alam ${ }^{1, ~}$, Md. Abdul Alim² \\ ${ }^{1}$ Department of Mathematics, Dhaka University of Engineering \& Technology, Gazipur, Bangladesh \\ ${ }^{2}$ Department of Mathematics, Bangladesh University of Engineering and Technology, Dhaka, Bangladesh \\ Email address: \\ mollah123@yahoo.com (Md. S. H. Mollah), shdlalam agmail.com (Md. S. Alam), a0alim@gmail.com (Md. A. Alim) \\ ${ }^{*}$ Corresponding author
}

\section{To cite this article:}

Md. Shirazul Hoque Mollah, Md. Shahidul Alam, Md. Abdul Alim. Numerical Simulation of Natural Convection in a Rectangular Cavity with Heated Triangle and Internal Heat Generation. International Journal of Theoretical and Applied Mathematics.

Vol. 5, No. 3, 2019, pp. 44-56. doi: 10.11648/j.ijtam.20190503.12

Received: August 9, 2019; Accepted: September 18, 2019; Published: October 9, 2019

\begin{abstract}
Free convection flow and heat transfer in a rectangular cavity with heated triangle and internal heat generation is investigated numerically. A finite element analysis is performed to investigate the effects of uniform heating and is also used for solving the Navier-Stokes and Energy balance equations. The horizontal bottom wall is divided into three equal sections. The middle section of the horizontal bottom wall, bottom side of the triangle and left vertical left wall in the enclosure were kept temperature at $T_{h}$. The other two parts of the horizontal bottom wall and the other two sides of the triangle were kept thermal insulation while the right vertical walls and the top wall of the cavity were maintained constant temperature $T_{c}$ with $\mathrm{T}_{\mathrm{h}}>\mathrm{T}_{\mathrm{c}}$. The physical problems are represented mathematically by different sets of governing equations along with corresponding boundary conditions. The dimensionless Parameters in the equations are performed for Heat generation $(\lambda)$, Rayleigh number $(R a)$ and Prandtl number $(P r)$. The streamlines, isotherms, average Nusselt number, velocity profiles and temperature distribution of the fluid in the enclosure are presented graphically. The numerical results indicate that the Heat Generation and Rayleigh number have strong influence on the streamlines and isotherms. Also the mentioned parameters have significant effect on average Nusselt number at the hot wall and average temperature of the fluid in the enclosure.
\end{abstract}

Keywords: Finite Element Method, Heat Generation, Numerical Simulation, Natural Convection, Rectangle Cavity

\section{Introduction}

Natural convection in closed cavities is one of the most important subjects of fluid flow and heat transfer. This subject has received much attention in last few years due to many energy-related applications, such as cooling of electronic components, thermal insulation of buildings using air gaps, solar energy collectors, semiconductor production, furnaces and fire control in buildings. Convection due to buoyancy forces is an important and often dominant mode of heat and mass transport.

Ahmed Kadhim Hussein [1] developed finite volume simulation of natural convection in a trapezoidal cavity filled with various fluids and heated from the top wall. He found that at low Rayleigh number, the circulation pattern in the trapezoidal cavity is very weak because the viscous forces are dominating over the buoyancy forces. As Rayleigh number increases, a clear confusion occurs in the shape of recirculating vortices, since the buoyancy forces are dominating over the viscous forces. Azad et al. [2] analyzed combined convection in an open cavity under constant heat flux boundary conditions and magnetic field using finite element method. They observed that Hartmann number decreases the flow strength and convection. Thus, the heat transfer regime becomes conduction for higher values of Hartmann numbers even at high Rayleigh numbers. Bouabid et al. [3] investigated irreversibility on MHD natural convection in a square cavity for different Prandtl numbers. Natural convection in a triangular top wall enclosure with a solid strip was studied by Ahmed kadhim et al. [4]. It was 
concluded by them due to the presence of the solid adiabatic strip, the lower portion of the cavity remains very cold compared to the upper portion. Chowdhury et al. [5] performed natural convection in porous triangular enclosure with a circular obstacle in presence of heat generation. They observed that the fluid flow and temperature field strongly depend on the presence of the circular body obstructs the flow and temperature fields. The heat generation effect is negligible for large size of circular body. Nejad and Keshtkar [6] developed entropy generation analysis of natural convection in square enclosures with two heat source. Khudheyer [7] developed MHD mixed convection in double lid- driven differentially heated trapezoidal cavity. Aghaei et al. [8] analyzed of magnetic field effects on distributed heat sources in a nanofluid-filled enclosure by natural convection. Basak et al. [9] investigated energy flows due to natural convection within trapezoidal enclosures with hot bottom wall and cold side walls in the presence of insulated top walls. Jani et al.[10] developed magneto hydrodynamic free convection in a square cavity heated from below and cooled from other walls. Alam et al. [11] established finite element analysis of MHD natural convection in a rectangular cavity and partially heated wall. They found that heat transfer mechanism, temperature distribution and the flow characteristics inside the cavity depended strongly upon both the strength of the magnetic field and the Rayleigh number. Alam et al. [12] formulated numerical simulation of natural convection in a rectangular cavity with triangles of different orientation in presence of magnetic field. Where we found the orientation of triangular heated body has an effect on the flow and temperature fields. Alam et al. [13] investigated numerical simulation of natural convection in a rectangular cavity with corner heater in presence of magnetic field. Alam et al. [14] analyzed effect of Prandtl number on magnetoconvection in a lid driven square cavity with a sinusoidal vertical wall. They concluded that the Prandtl number thermal diffusivity dominates, this means that conduction dominates over convection. Alam et al. [15] performed mixed magneto convection in a lid driven square enclosure with a sinusoidal vertical wall and joule heating. Ali et al. $[16,17]$ performed numerical study of mixed and free convection in hexagonal and square enclosure in presence of magnetic field. Later on, Sarkar [18] and Hossain [19] extended theses analysis for the rectangular enclosure with different thermal conditions. B. Xu, et al. [20] developed an experimental study of thermally induced convection of molten gallium in magnetic fields. They found that natural convection is suppressed with an imposed magnetic field and the magnetic damping effect increases with an increase in the applied field strength.

The above literature review observed that no work has yet been done on numerical simulation of natural convection in a rectangular cavity with heated triangle and internal heat generation. The dimensionless Parameters in the equations are performed for Heat generation $(\lambda)$, Rayleigh number $(R a)$ and Prandtl number $P r$. The results are presented in terms of streamlines and isotherms inside the cavity, vertical component of the velocity along the horizontal centerline of the cavity, local Nusselt number along the hot wall, and average Nusselt number of the hot wall also.

\section{Physical Model and Mathematical Formulations}

A schematic of the problem considered in present study is shown in Figure 1. The system consist of a rectangular cavity with a heated triangle is located inside the enclosure. The middle section of the horizontal bottom wall, left vertical wall and bottom side of the triangle in the enclosure were kept temperature at $T_{h}$ and the other two parts of the horizontal bottom wall and the rest two side of the triangle were kept thermal insulation while the right vertical walls and the top wall of the cavity were maintained constant temperature $T_{c}$, where $T_{c}$ is less than $T_{h}$. The fluid is considered as incompressible and the flow is assumed to be laminar. The boundary conditions for velocity are considered as no-slip on solid boundaries. The volumetric rate of heat generation $\mathrm{q}\left[\mathrm{W} / \mathrm{m}^{3}\right] \quad$ is $q=\mathrm{Q}_{0}\left(T-T_{c}\right)$, for $T \geq T_{c} \quad$ and $q=0$, for $T \leq T_{c}$ Where $\mathrm{Q}_{0}$ is a heat generation constant which may be either positive or negative. This source term represents the heat generation when $\mathrm{Q}_{0}>0$ and the heat absorption when $\mathrm{Q}_{0}<0$. Steady two-dimensional laminar free convective flow of viscous incompressible fluid having constant properties is assumed; where buoyancy effect is included through Boussinesq approximation. The gravitational acceleration acts in the negative $y$-direction. All solid boundaries are assumed to be rigid no-slip walls.

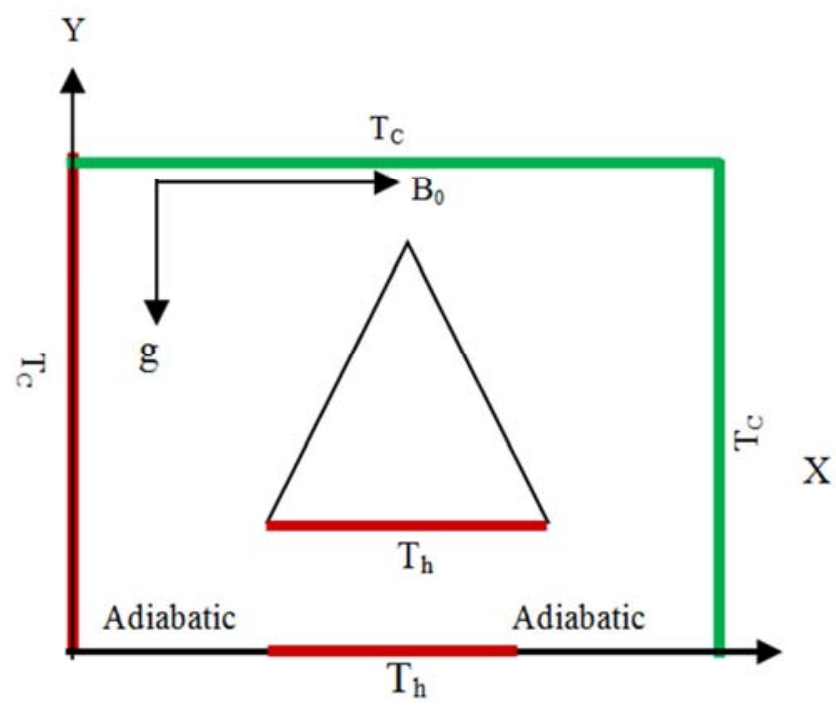

Figure 1. Schematic diagram of the physical system.

Under these assumptions the equations of Continuity, momentum and energy are:

Continuity Equation:

$$
\frac{\partial u}{\partial \bar{x}}+\frac{\partial v}{\partial \bar{y}}=0
$$


Momentum Equations

$$
\begin{array}{r}
\rho\left(u \frac{\partial u}{\partial x}+v \frac{\partial u}{\partial y}\right)=-\frac{\partial p}{\partial x}+\mu\left(\frac{\partial^{2} u}{\partial x^{2}}+\frac{\partial^{2} u}{\partial y^{2}}\right) \\
\rho\left(u \frac{\partial v}{\partial x}+v \frac{\partial v}{\partial y}\right)=-\frac{\partial p}{\partial x}+\mu\left(\frac{\partial^{2} v}{\partial x^{2}}+\frac{\partial^{2} v}{\partial y^{2}}\right)+\rho g \beta(T-T c)
\end{array}
$$

Energy equations

$$
u \frac{\partial T}{\partial x}+v \frac{\partial T}{\partial y}=\alpha\left(\frac{\partial^{2} T}{\partial x^{2}}+\frac{\partial^{2} T}{\partial y^{2}}\right)
$$

where $\mathrm{x}$ and $\mathrm{y}$ are the distances measured along the horizontal and vertical directions respectively; $u$ and $v$ are the velocity components in the $\mathrm{x}$ and $\mathrm{y}$ directions respectively; $\mathrm{T}$ denotes the fluid temperature and $T_{c}$ denotes the reference temperature for which buoyant force vanishes, $p$ is the pressure and $\rho$ is the fluid density, $g$ is the gravitational acceleration $\beta$ is the volumetric coefficient of thermal expansion, $C_{p}$ is the specific heat at constant pressure. The above equations will be making dimensionless, we introduce the following non-dimensional variables are as follows:

$$
\begin{aligned}
& X=\frac{x}{H}, Y=\frac{y}{H}, \mathrm{~L}=\frac{l_{h}}{H}, U=\frac{u H}{v}, \\
& V=\frac{v H}{v}, \quad P=\frac{p H^{2}}{\rho v^{2}}, \quad \theta=\frac{T-T_{c}}{T_{h}-T_{c}}
\end{aligned}
$$

where $v\left(=\frac{\mu}{\rho}\right)$ the reference kinematic viscosity and $\theta$ is the non-dimensional temperature. After substitution of dimensionless variables (5) into equations (1)-(4) the nondimensional governing equations for steady two-dimensional free convection flow in the rectangular cavity are as follows:

Continuity Equation

$$
\frac{\partial U}{\partial X}+\frac{\partial V}{\partial Y}=0
$$

Momentum Equations

$$
\begin{gathered}
U \frac{\partial U}{\partial X}+V \frac{\partial U}{\partial Y}=-\frac{\partial P}{\partial X}+\left(\frac{\partial^{2} U}{\partial X^{2}}+\frac{\partial^{2} U}{\partial Y^{2}}\right) \\
U \frac{\partial V}{\partial X}+V \frac{\partial V}{\partial Y}=-\frac{\partial P}{\partial Y}+\frac{1}{\operatorname{Re}}\left(\frac{\partial^{2} V}{\partial X^{2}}+\frac{\partial^{2} V}{\partial Y^{2}}\right)+\frac{R a}{\operatorname{Pr}} \theta
\end{gathered}
$$

Energy Equations

$$
U \frac{\partial \theta}{\partial X}+V \frac{\partial \theta}{\partial Y}=\frac{1}{\operatorname{Pr}}\left(\frac{\partial^{2} \theta}{\partial X^{2}}+\frac{\partial^{2} \theta}{\partial Y^{2}}\right)+\lambda \theta
$$

In the above equations $\mathrm{Ra}$ is the Rayleigh number, $\mathrm{Pr}$ is the number and the heat generation parameter defined by the following relations

$$
R a=\frac{\beta\left(T_{h}-T_{c}\right) H^{3}}{\alpha v}, \operatorname{Pr}=\frac{v}{\alpha}, \lambda=\frac{Q_{0} H^{2}}{\mu c_{p}}
$$

The non-dimensional boundary conditions under consideration can be written as:

At the solid walls and triangular body surface:

$U=0, V=0, \frac{\partial \theta}{\partial N}=0$. At the top and right vertical walls: $U=0, V=0$ and $\theta=0$ At the right and left section of the bottom wall: $\frac{\partial \theta}{\partial N}=0$ At the heated walls' $=0, V=0$ and $\theta=1$ where $\mathrm{X}$ and $\mathrm{Y}$ are dimensionless coordinates varying along horizontal and vertical directions, respectively; $\mathrm{U}$ and $\mathrm{V}$ are dimensionless velocity components in $\mathrm{X}$ and $\mathrm{Y}$ directions, respectively; $\theta$ is the dimensionless temperature where $\mathrm{N}$ is the non-dimensional distances either along $\mathrm{X}$ or $\mathrm{Y}$ direction acting normal to the surface. The local Nusselt number at the heated surface of the cavity which is defined by the following expression $N u_{l}=N u_{r}=N u_{b}=N u_{s}=-\frac{\partial \theta}{\partial N}$ where $\mathrm{n}$ denotes the normal direction on a plane.

\section{Numerical Analysis}

The numerical procedure used to solve the governing equations for the present work is based on the Galerkin weighted residual method of finite-element formulation. The non-linear parametric solution method is chosen to solve the governing equations. This approach will result in substantially fast convergence assurance. A non-uniform triangular mesh arrangement is implemented in the present investigation to capture the rapid changes in the dependent variables. The velocity and thermal energy equations (1)-(4) result in a set of non-linear coupled equations for which an iterative scheme is adopted. To ensure convergence of the numerical algorithm the following criteria is applied to all dependent variables over the solution domain $\sum\left|\psi_{i j}^{n}-\psi_{i j}^{n-1}\right| \leq 10^{-5}$ where Yrepresents a dependent variable $U, V, P$, and $T$; the indexes $i$, $j$ indicate a grid point; and the index $\mathrm{n}$ is the current iteration at the grid level. The six node triangular element is used in this work for the development of the finite element equations. All six nodes are associated with velocities as well as temperature; only the corner nodes are associated with pressure. This means that a lower order polynomial is chosen for pressure and which is satisfied through continuity equation. These residuals are reduced to zero in a weighted sense over each element volume using the Galerkin method. Details of the method are available in Taylor and Hood (1973) and Dechaumphai (1999).

\section{Grid Independent Test}

In order to obtain grid independent solution, a grid refinement study is performed for a rectangular cavity with 
$\operatorname{Pr}=0.71, \phi=0^{0}$ and $R a=10^{5}$. Figure 2 shows the convergence of the average Nusselt number, $\mathrm{Nu}_{\mathrm{av}}$ at the heated surface with grid refinement. It is observed that grid independence is achieved with 2271 elements where there is insignificant change in $\mathrm{Nu}$ with further increase of mesh elements. Six different non-uniform grids with the following number of nodes and elements were considered for the grid refinement tests: 132 nodes, 230 elements; 241nodes, 409 elements; 374 nodes, 655 elements; 691 nodes, 1253 elements; 2271 nodes, 4300 elements; 80732 nodes, 16982 elements. From these values, 2271 nodes 4300 elements can be chosen throughout the simulation to optimize the relation between the accuracy required.

Table 1. Grid Sensitivity Check at $\mathrm{Pr}=0.7, \phi=0, \mathrm{Ha}=50$ and $\mathrm{Ra}=10^{5}$.

\begin{tabular}{lllllll}
\hline Nodes & 132 & 241 & 374 & 691 & 2271 & 8732 \\
Elements & 230 & 409 & 655 & 1253 & 4300 \\
$N u$ & 2.2423 & 2.77928 & 3.43519 & 3.88108 & 4.62028 \\
$\theta_{\text {av }}$ & 0.31173 & 0.30403 & 0.29903 & 0.29431 & 4.62003 & 0.28732 \\
\hline
\end{tabular}

$\mathrm{Nu}$

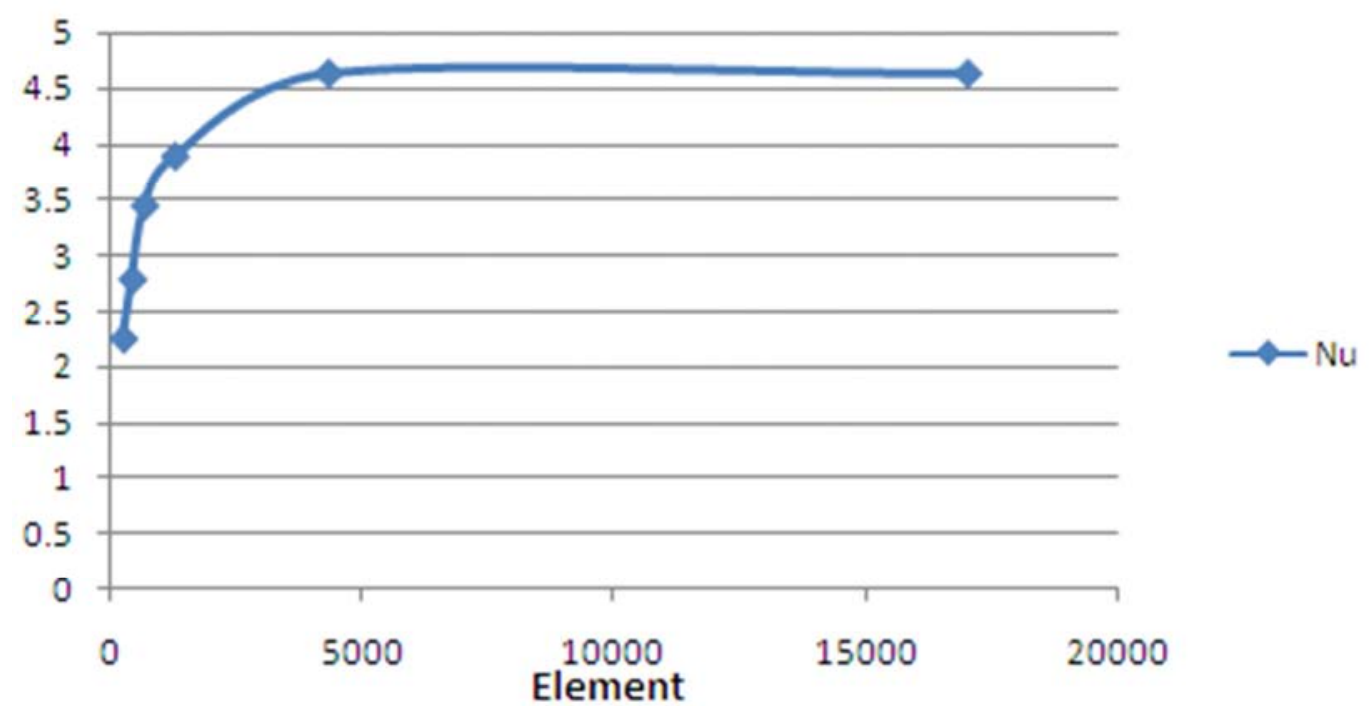

Figure 2. Graph of average Nusselt Number.

\section{Comparison/Validation}

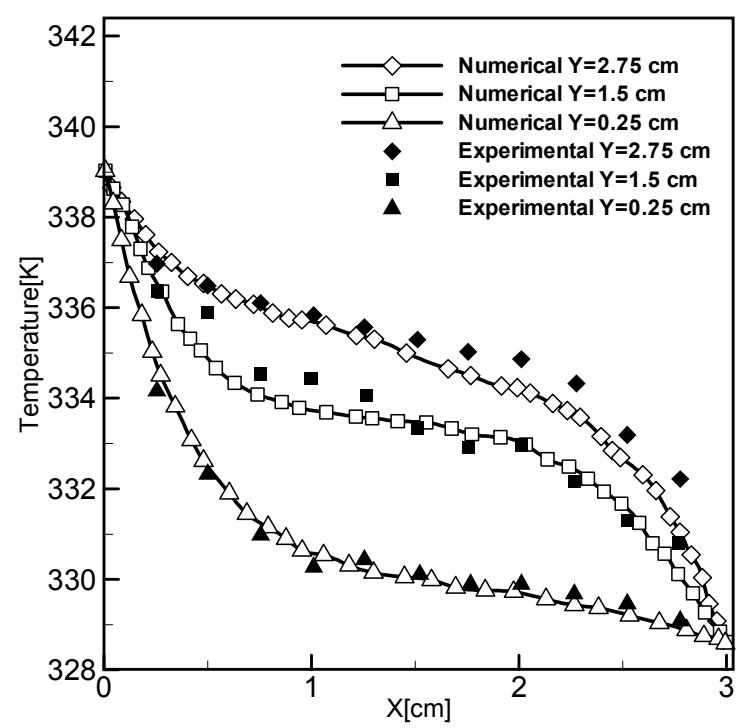

Figure 3. Comparison of present numerical result with experimental data of B. Xu et al. [20].
The Figure 3: comparison of present numerical result with experimental data of $\mathrm{B}$. Xu et al. [20]. The present research describes the numerical study and compares the finding results with the experimental measurements. The experimental investigation is on natural convection in a molten metal subject to a uniform magnetic field. The working fluid is molten gallium, which is contained in a rectangular box with the two opposite vertical walls held at different temperatures. The left and right vertical walls are constant different temperature $T_{h}$ and $T_{c}$ hot and cold respectively. The hot temperature $T_{h}=$ $339 \mathrm{~K}$ and cold temperature $T_{c}=328 \mathrm{~K}$, giving a temperature difference $\Delta \mathrm{T}=11 \mathrm{~K}$. The measured and computed temperature profiles with applied magnetic fields 300 Gauss are shown in the Figure 3. The temperature profiles across the width of the cell are plotted for $Y=2.75 \mathrm{~cm}, 1.5 \mathrm{~cm}$ and 0.25 $\mathrm{cm}$. The present study has also taken left and right vertical walls are constant different temperature $T_{h}$ and $T_{c}$ hot and cold respectively. The experimental and numerical results show a good agreement.

\section{Results and Discussions}

Laminar natural convection heat transfer and fluid flow 
are studied in a rectangle enclosure for different parameters Rayleigh number and heat generation parameter. Heater position of the cavity is partially heated horizontal bottom wall, horizontal side of the triangle and left vertical wall as shown in Figure 1. The mentioned parameters having the following ranges: Rayleigh number from $10^{3}$ to $10^{6}$ and Heat generation parameter $(\lambda)$ are $0.15,10$ and 20. Air is chosen as a fluid with Prandtl number 0.71. The results are presented in terms of streamlines and isotherms inside the cavity, the vertical velocity component, dimensionless temperature, the local Nusselt number along the horizontal line $y=0.3$ of the cavity. Moreover, the variation of the average Nusselt number at the heated surface and average fluid temperature in the cavity are also highlighted in tabular form

\subsection{Effect of Rayleigh Number}

Figure $4 \&$ Figure 6 and Figure $5 \&$ Figure 7 depicted Streamlines and isotherms respectively for variation of $R a=$ 1000, 10000, 100000 and 1000000. While Heat generation parameter $\lambda=0.0$ and 1.5 are used for Figure $4 \&$ Figure 5 and Figure $6 \&$ Figure 7 respectively, and $\operatorname{Pr}=0.71$. It is observed the effect of Rayleigh number in the flow field and temperature distribution. For both values of Heat generation $(\lambda=0.0$ and 1.5) two elliptic-shaped cells are formed of stream lines for different values of Rayleigh number. Cells are seen both sides of triangular block at the inclined side in the cavity. For increasing of Rayleigh number both cells changes their shape and position towards middle part of the cavity. Stream function has symmetrical value about vertical and horizontal wall. Isotherms lines are often parallel among themselves about the vertical and top wall. For higher values of Rayleigh number isotherms are condensed to the top and right wall because of heated left and bottom wall. In addition, a thermal boundary layer starts to develop near the cold wall. This is because, at the highest Rayleigh number, natural convection is more effective than that of conduction. On the other hand, at the lower values of $R a\left(=10^{3}, 10^{4}\right)$ the isotherms near the left wall are almost similar but dissimilar near the right wall. The left elliptic vortex is about to absence at $R a(=100000)$ on both cases that is $\lambda=0.0$ and $\lambda=1.5$. Streamlines is becoming stronger than higher values of Heat generation parameter. Heat generation parameter has significance effect in the flow and temperature field. Figure $8 \&$ Figure 9 represent velocity, Figure $10 \&$ Figure 11 represent temperature and Figure $12 \&$ Figure 13 representthe local Nnusselt number. From Figure $8 \&$ Figure 9 velocity profile is observed. Highest and lowest velocity is observed in both cases for Heat generation parameters $\lambda=0.0$ and 1.5. From higher values of Heat generation temperature increases is shown in Figure $10 \&$ Figure 11. The rate of heat transfer decreases for higher values of Rayleigh number is seen in Figure 12 \& Figure 13.

\subsection{Effect of Heat Generation}

Now we discuss the effect of the internal heat generation parameter $(\lambda)$ on the flow and thermal fields in the cavity. Figure $14 \&$ Figure 16 and Figures $15 \& 17$ depicted Streamlines and isotherms for variation of $\lambda=0.1,5,10$, and 20 while Rayleigh number $R a=10000$ and 100000 respectively and $P r=0.71$. Two elliptic shaped vortex are observed on both inclined side of the triangle in streamlines in Figure 14 and 16 where $R a=1000$ to. 1000000 . Vortexes of the right side are becoming stronger as increasing of Rayleigh number. On the other hand only one vortex on the left side of the triangle in the streamlines is seen weaker in Figure 16 where $R a=1000000$. Figure 14 depicts the streamlines for the values of heat generation parameter $\lambda=$ $0.0,10,15$ and 20 at the Rayleigh numbers $R a=10000$. From this figure it is seen that at the lower values of $R a$ (= $\left.10^{3}\right)$ and $\lambda(=0.0)$, a circle shaped circulation cell is found in the cavity, due to domination of conduction effects. From this figure, it is also seen that increasing values of heat generation leads increasing value in the centre of the circulation cell at the lower values of $\mathrm{Ra}\left(=10^{3}\right)$. Moreover, the flow strength in the circulation cell also increases when the internal heat generation increases in magnitude at the higher values of $\mathrm{Ra}$ $\left(=10^{5}\right)$. The effect of different values of heat generation parameter on thermal field is depicted in Figure 14 for considered Rayleigh number $R a$, while flush heater placed at middle part of the horizontal bottom wall.

The isotherms near the wall are almost parallel for all values of heat generating parameter $\lambda$, but isotherms near the vicinity of the right vertical wall more concentrated with the increasing values of $\lambda$ at lower value of $R a$. The isotherm pattern of $R a=10^{4}$ for all values of $\lambda$ becomes more non linear while it compares with the lower values of $R a$, which is expected. Besides, at higher $R a\left(=10^{5}\right)$, a thermal spot is developed near the right vertical wall and becomes stronger but the concentrated isotherms near the heat source at the right vertical wall disappear with the increasing values of $\lambda$. The effects of heat generation parameter on the heat transfer rate along the hot wall is plotted as a function of Rayleigh number $R a$ in Figure 10 (a) \& (b) for the four different values of heat generating parameters $\lambda$. It is observed that average Nusselt number increases very slowly with the increase of $R a$ for the different values of heat generating parameters $\lambda$. It is also notes that $N u$ is always higher at $\lambda=0.0$, as expected. This is due to the fact that, the heat generation mechanism creates a layer of hot fluid near the hot surface as a result the increasing rate of internal heat generation negates the heat transfer from the hot surface. Figure $18 \&$ Figure 19, Figure $20 \&$ Figure 21 and Figure 22 \& Figure 23 depicted the velocity, temperature and local Nusselt number for variation of heat generation parameter $\lambda$ while $R a=10000$ or 100000 and $\operatorname{Pr}=0.71$. For increasing values of heat generation parameter rate heat transfer is increasing is observed in Figure 22 \& Figure 23. 


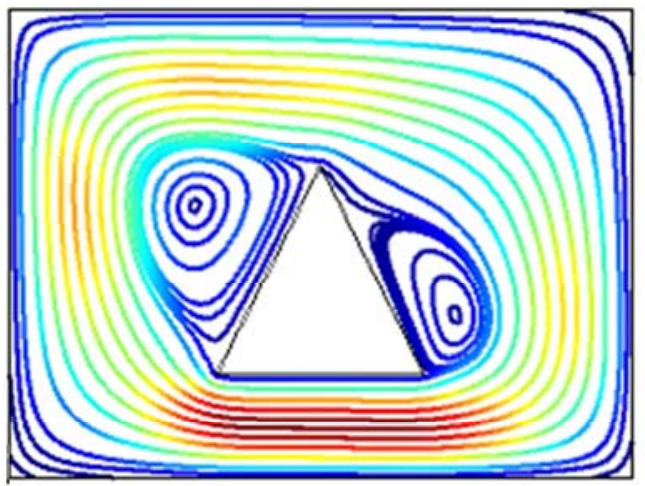

$\mathrm{Ra}=1000$

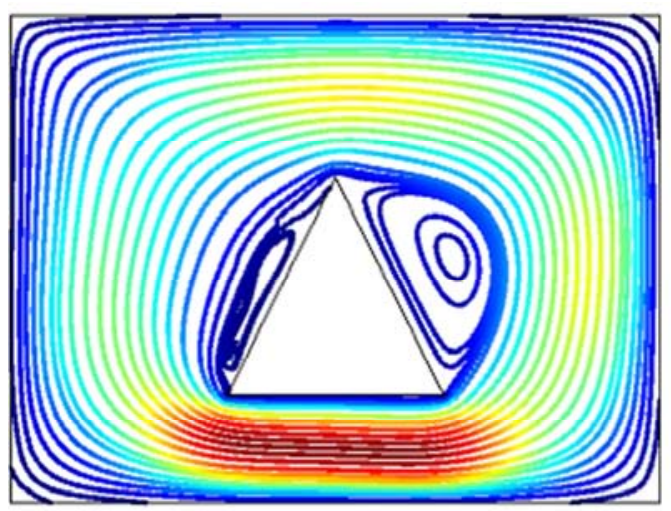

$\mathrm{Ra}=100000$

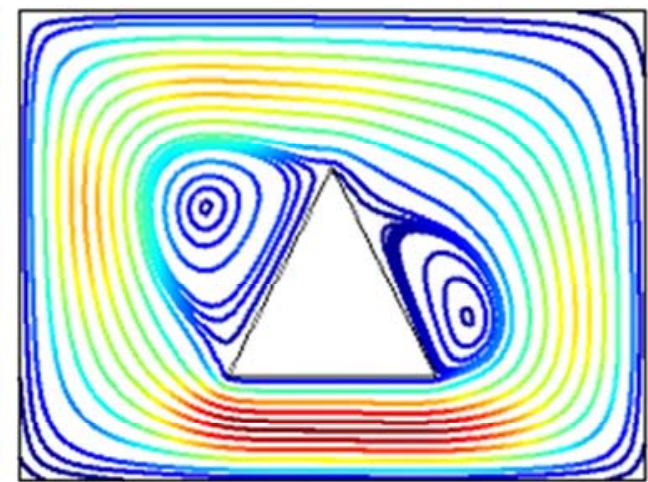

$\mathrm{Ra}=10000$

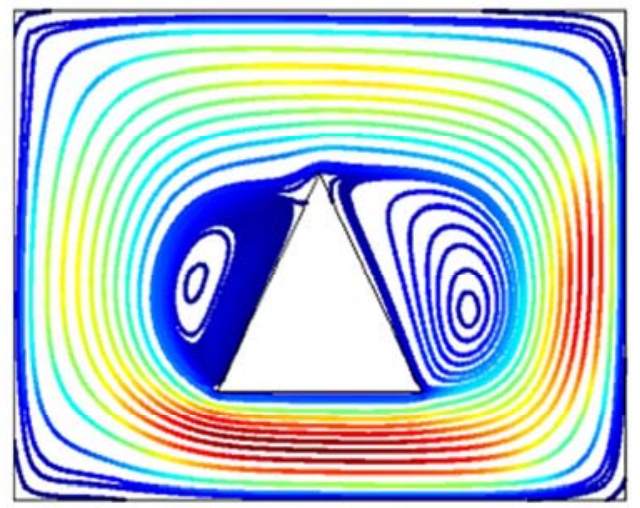

$\mathrm{Ra}=1000000$

Figure 4. Streamlines for variation of $R a=1000,10000,100000$ and 1000000, while $\lambda=0.0$ and $\mathrm{Pr}=0.71$.

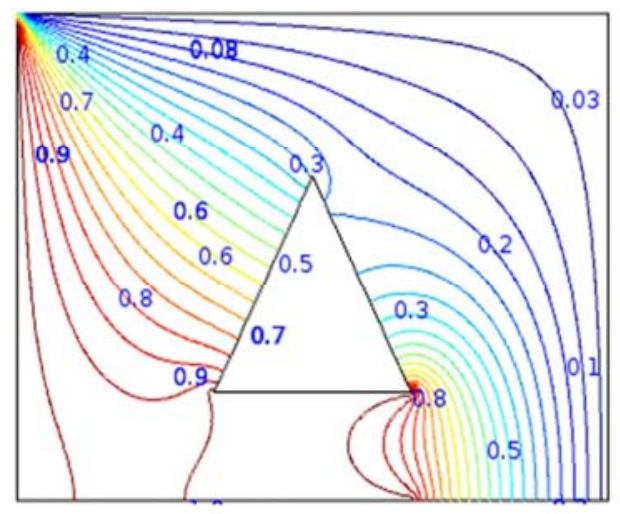

$\mathrm{Ra}=1000$

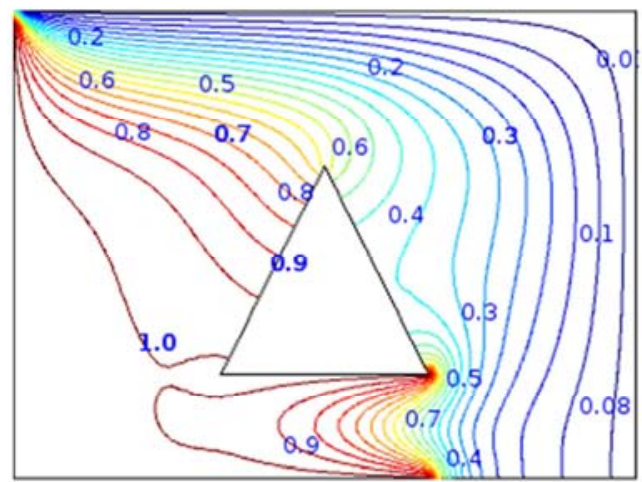

$\mathrm{Ra}=100000$

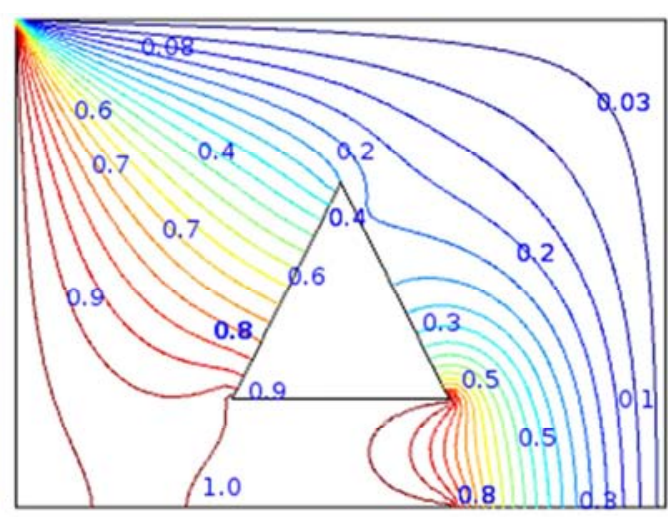

$\mathrm{Ra}=10000$

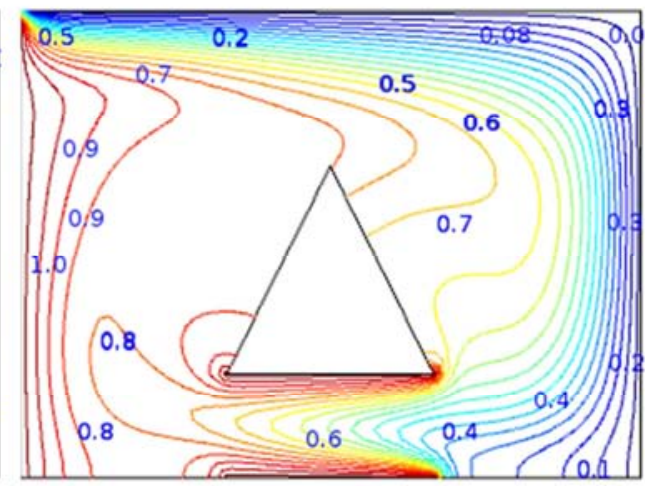

$\mathrm{Ra}=1000000$

Figure 5. Isotherms for variation of $R a=1000,10000,100000$ and 1000000, while $\lambda=0.0$ and $\operatorname{Pr}=0.71$. 


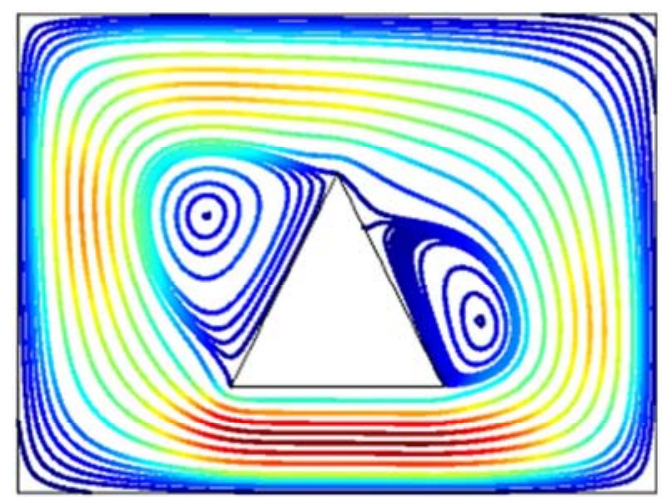

$\mathrm{Ra}=1000$

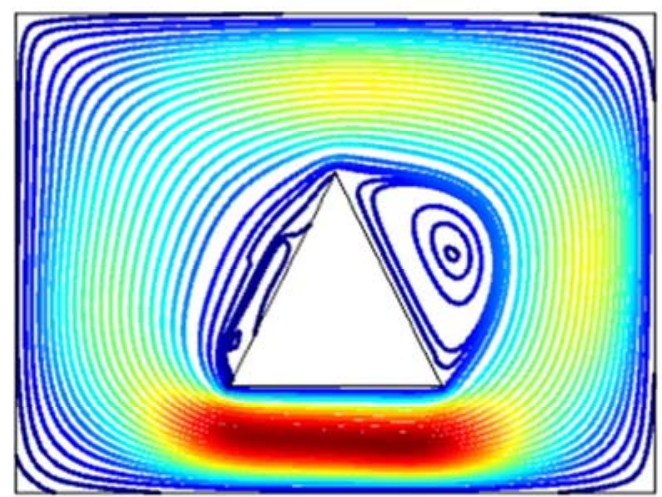

$\mathrm{Ra}=100000$

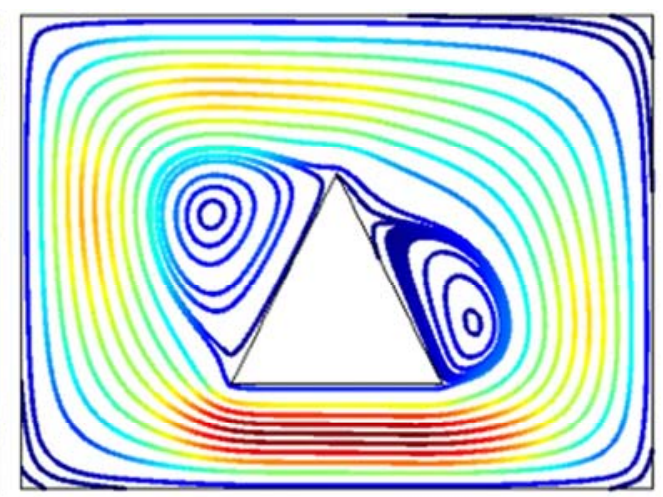

$\mathrm{Ra}=10000$

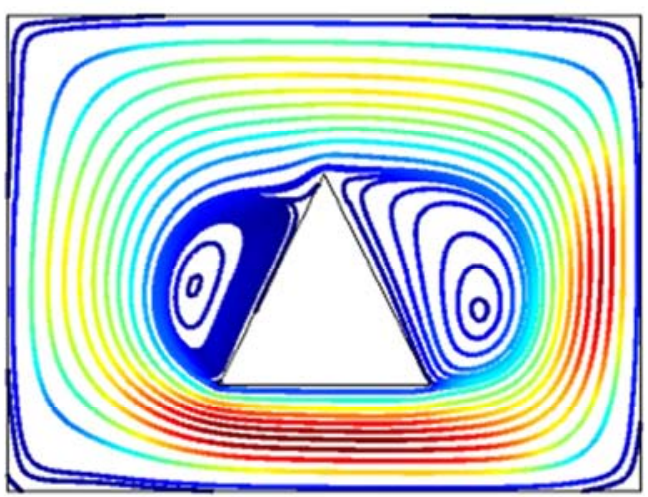

$\mathrm{Ra}=1000000$

Figure 6. Streamlines for variation of $R a=1000,10000,100000$ and 1000000 , while $\lambda=1.5$ and $\operatorname{Pr}=0.71$.

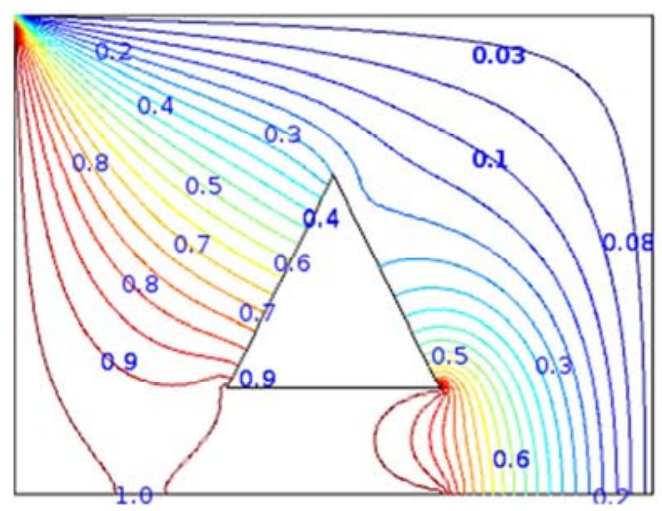

$\mathrm{Ra}=1000$

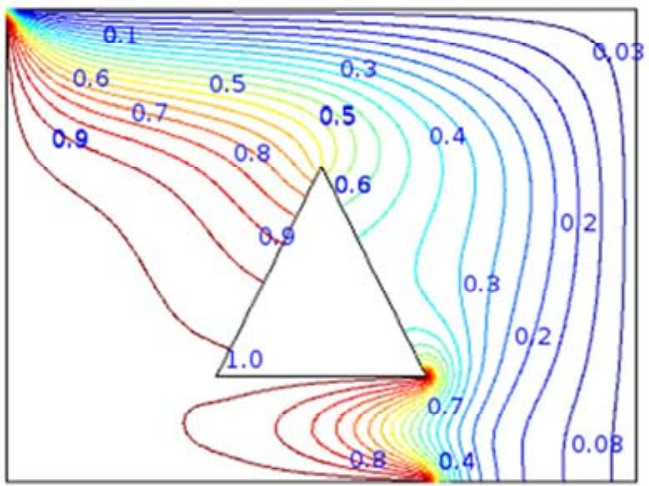

$\mathrm{Ra}=100000$

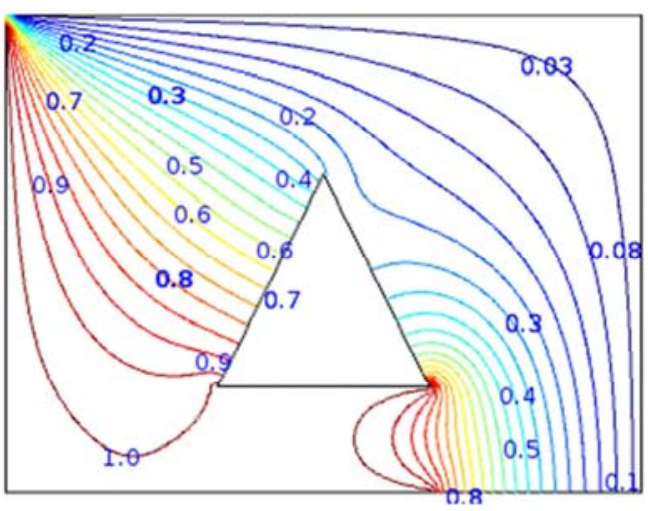

$\mathrm{Ra}=10000$

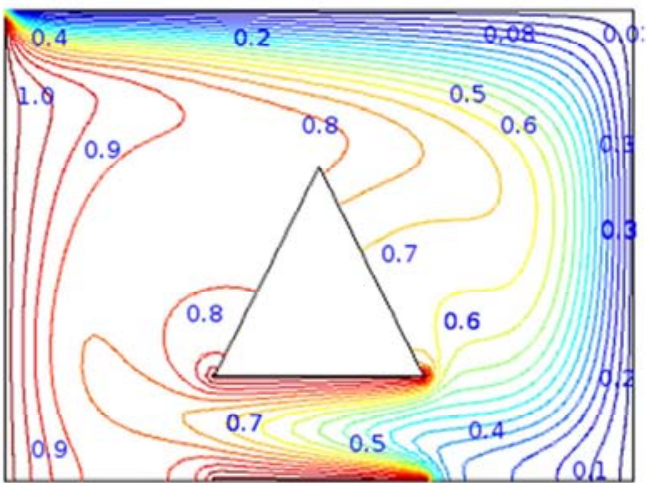

$\mathrm{Ra}=1000000$

Figure 7. Isotherms for variation of $R a=1000,10000,100000$ and1000000, while $\lambda=1.5$ and $\operatorname{Pr}=0.71$. 


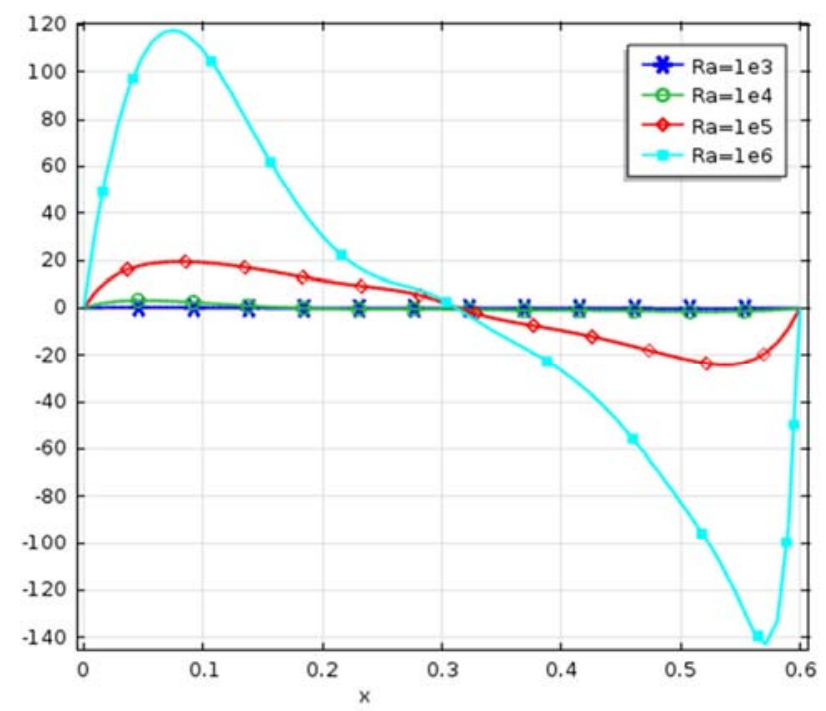

Figure 8. Veliocity graph for $\lambda=0.0$ along the line $y=0.3$.

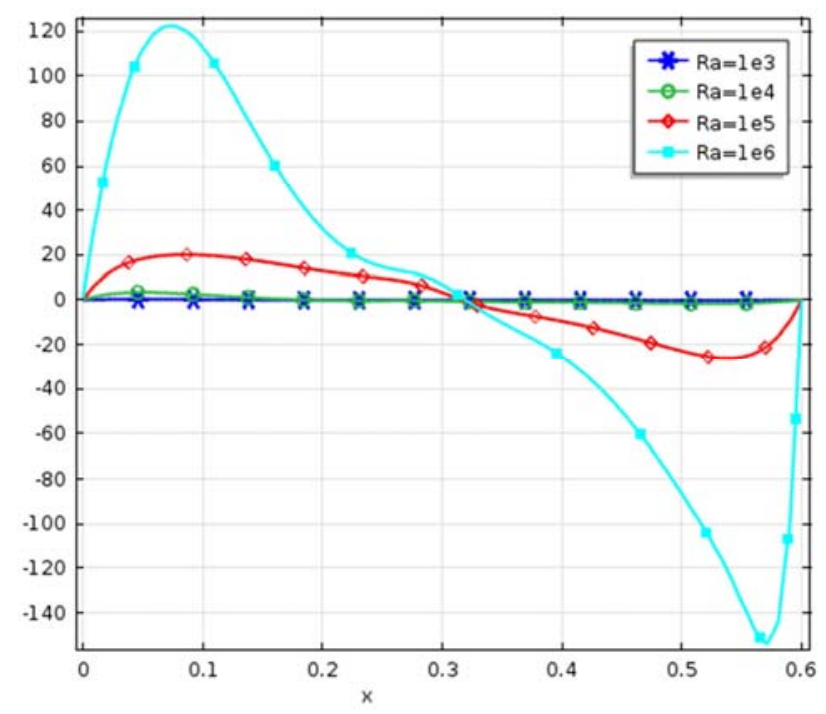

Figure 9. Veliocity graph for $\lambda=1.5$ along the line $y=0.3$.

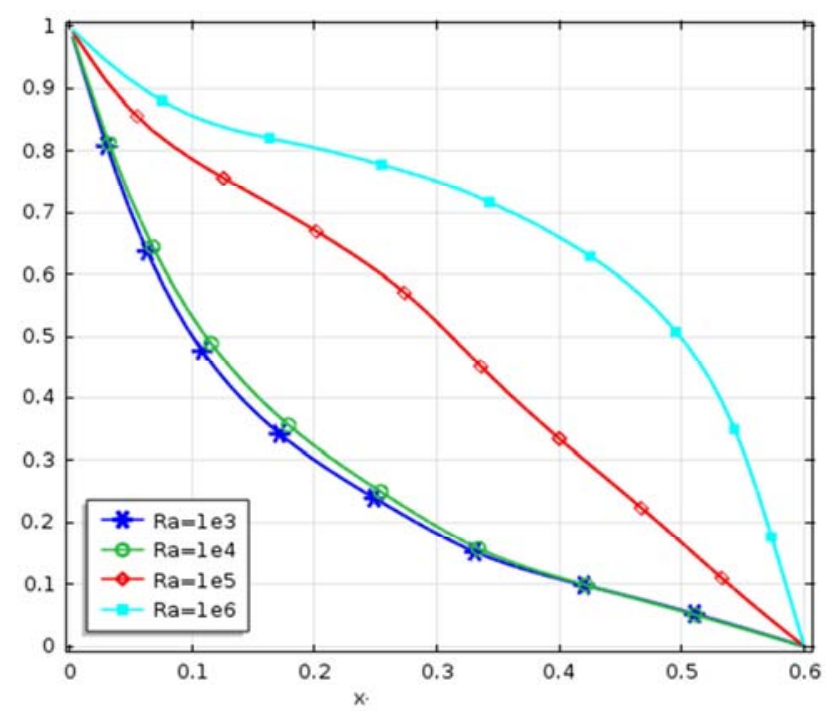

Figure 10. Temperature graph for $\lambda=0.0$ along the line $y=0.3$.

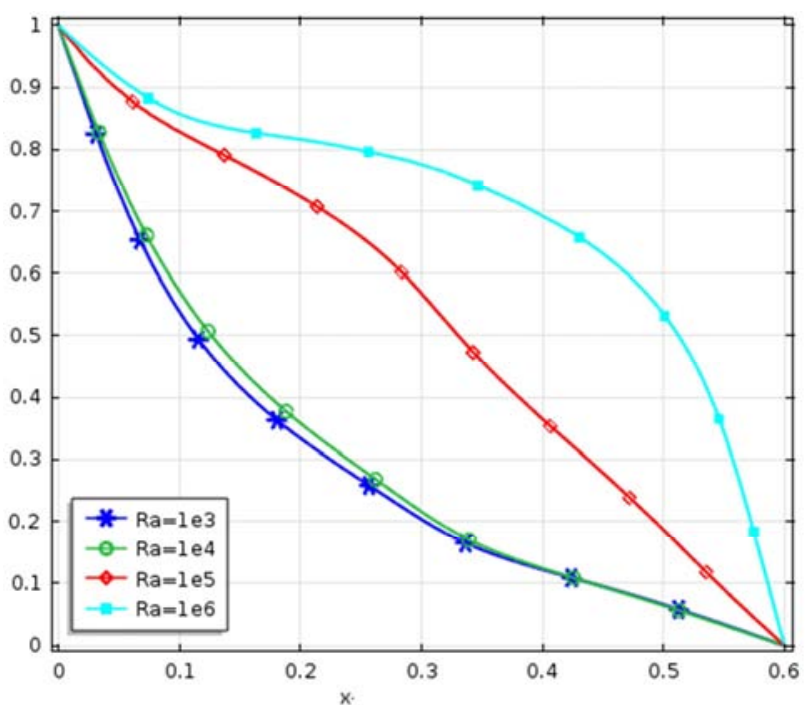

Figure 11. Temperature graph for $\lambda=1.5$ along the line $y=0.3$.

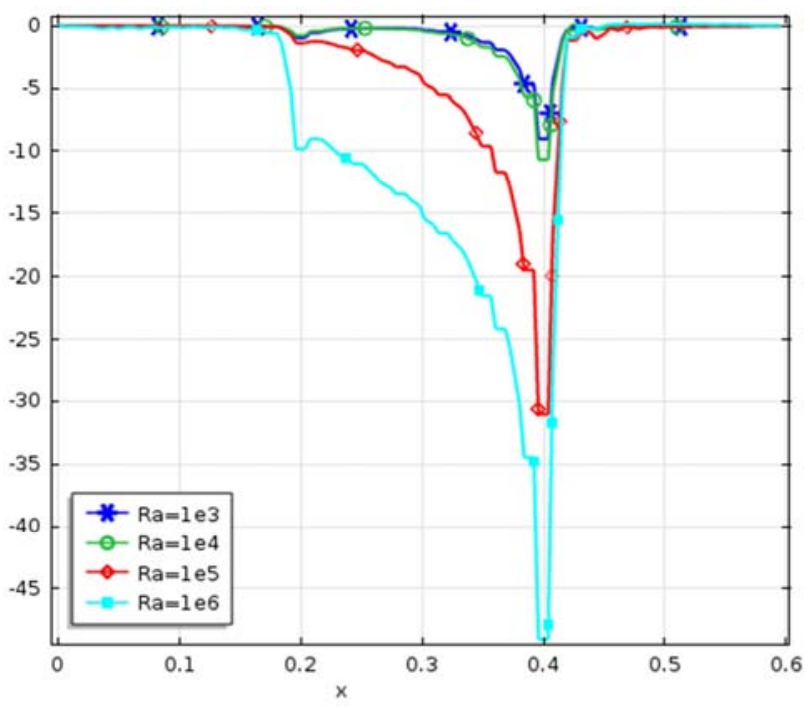

Figure 12. Local Nusselt number for $\lambda=0.0$ along the line the hot line.

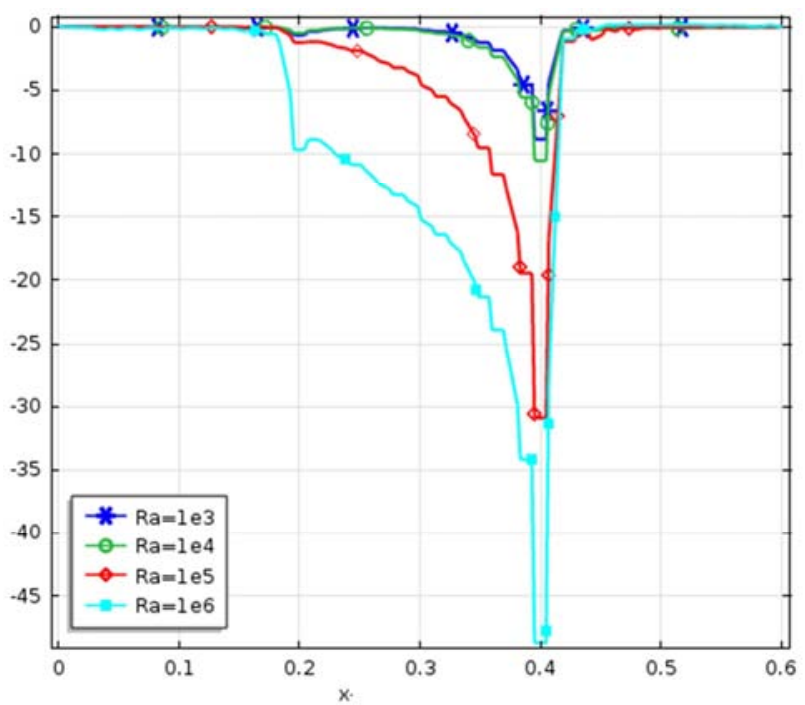

Figure 13. Local Nusselt number for $\lambda=1.5$ along the line the hot line. 


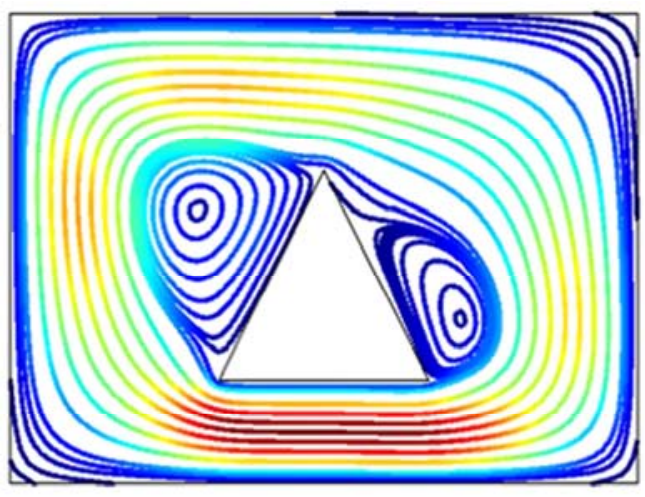

$\lambda=0.1$

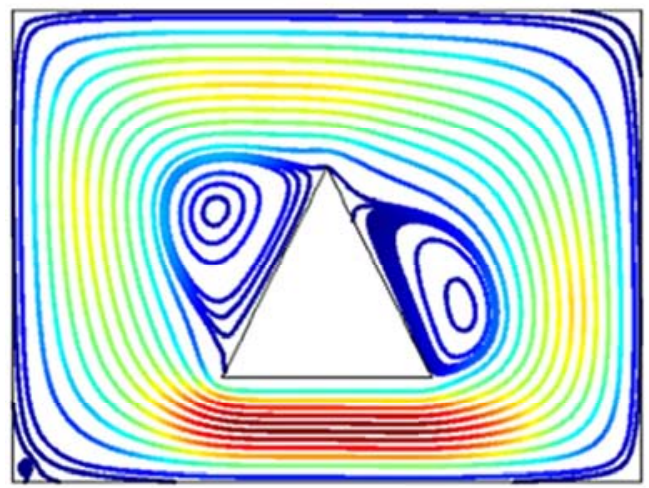

$\lambda=10$

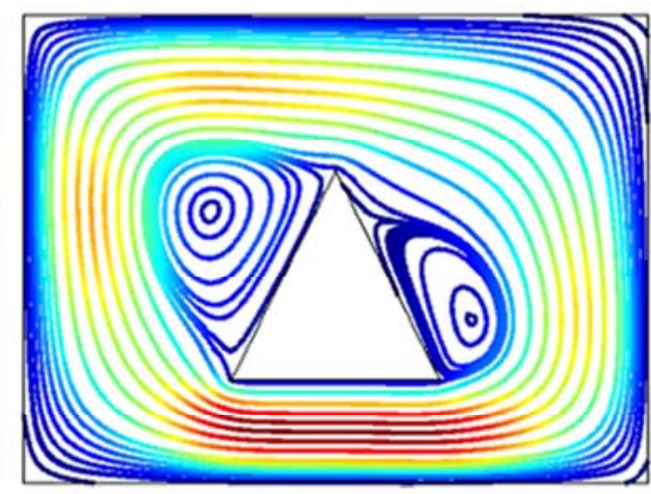

$\lambda=5$

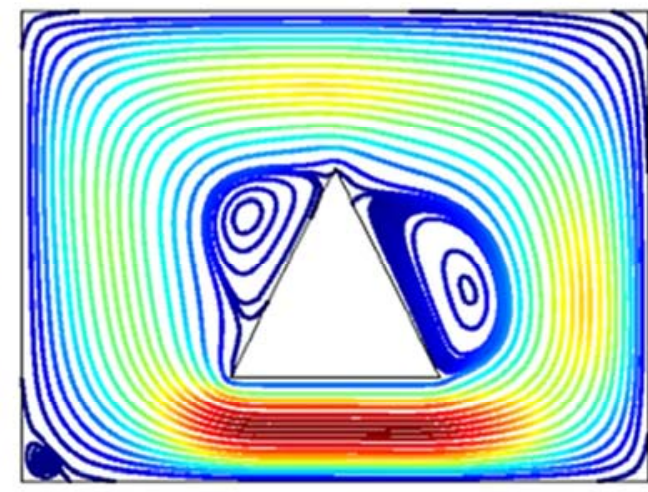

$\lambda=20$

Figure 14. Streamlines for variation of $\lambda=0.1,5,10$ and 20 while, $R a=10^{4}$ and $\mathrm{Pr}=0.71$.

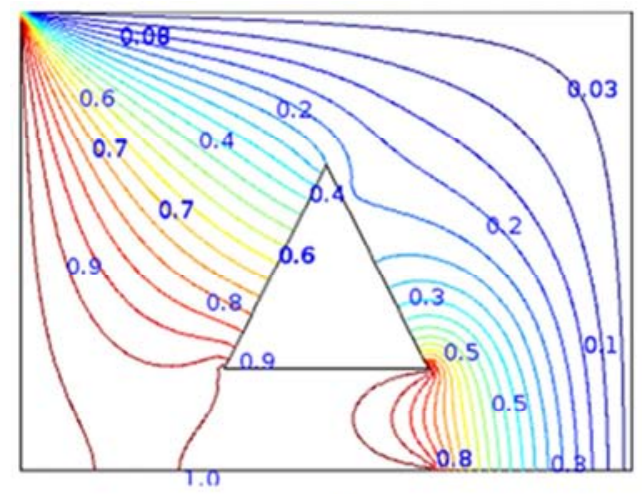

$\lambda=0.1$

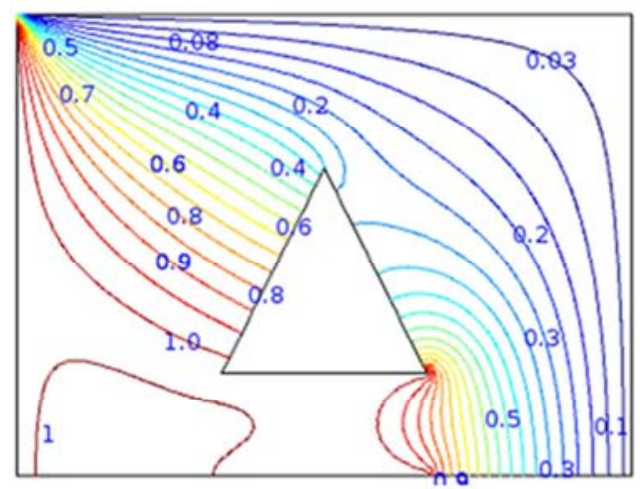

$\lambda=10$

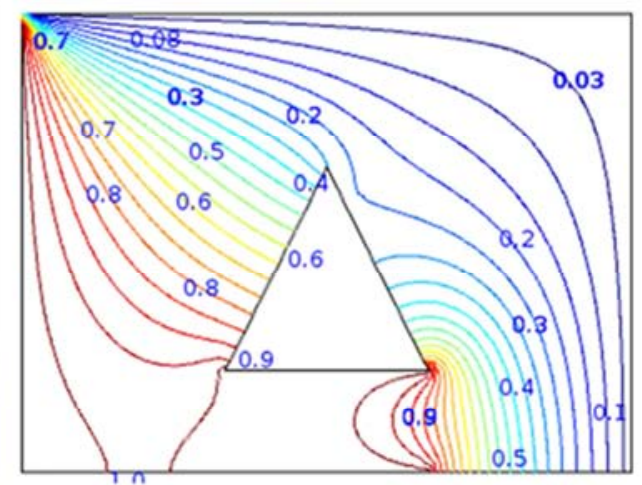

$\lambda=5$

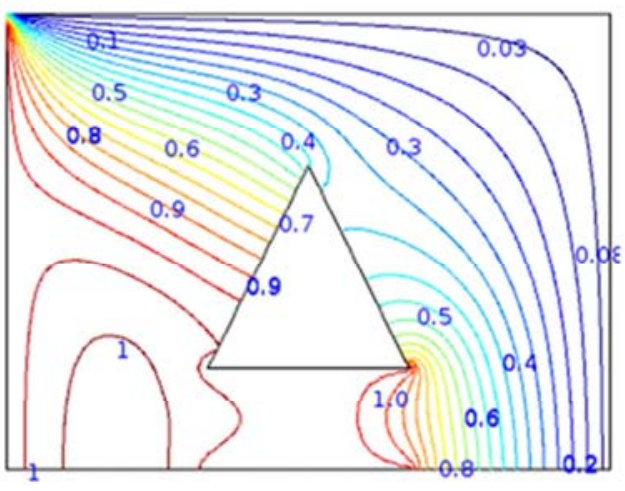

$\lambda=20$

Figure 15. Isotherms for variation of $\lambda=0.1,5,10$ and 20 while, $R a=10^{4}$ and $\operatorname{Pr}=0.71$. 


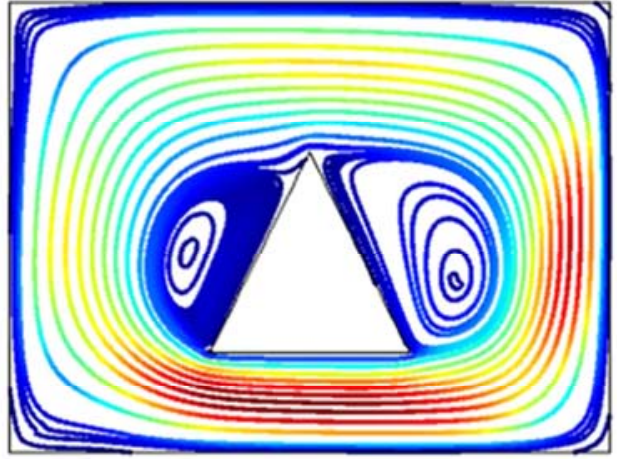

$\lambda=0.1$

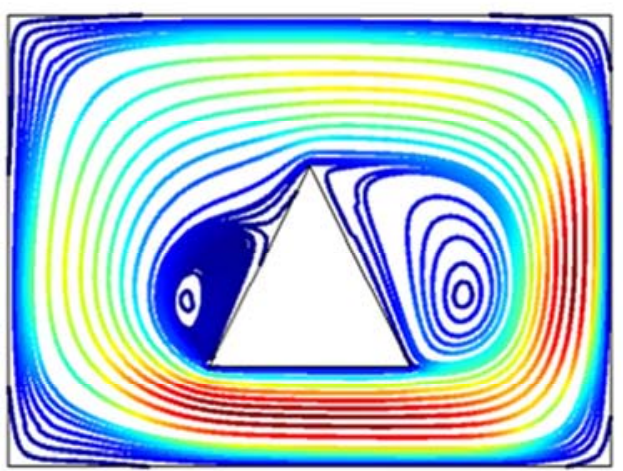

$\lambda=10$

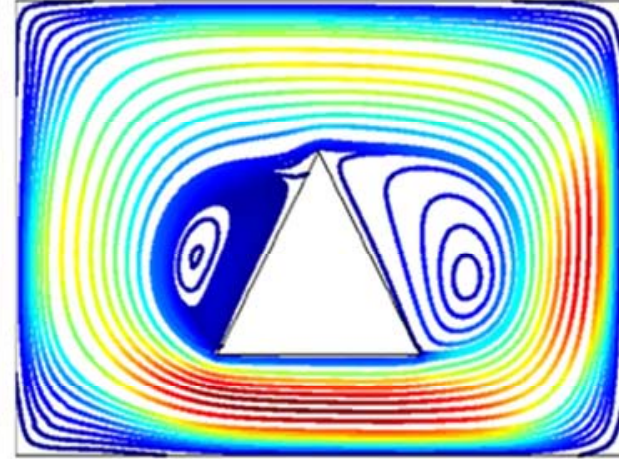

$\lambda=5$

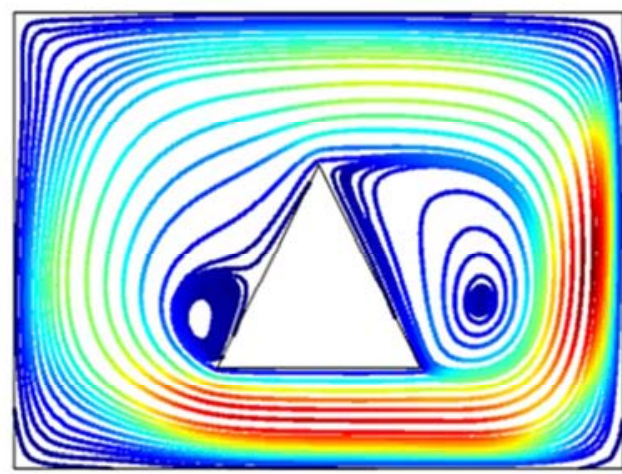

$\lambda=20$

Figure 16. Streamlines for variation of $\lambda=0.1,5,10$ and 20 while, $R a=10^{5}$ and $P r=0.71$
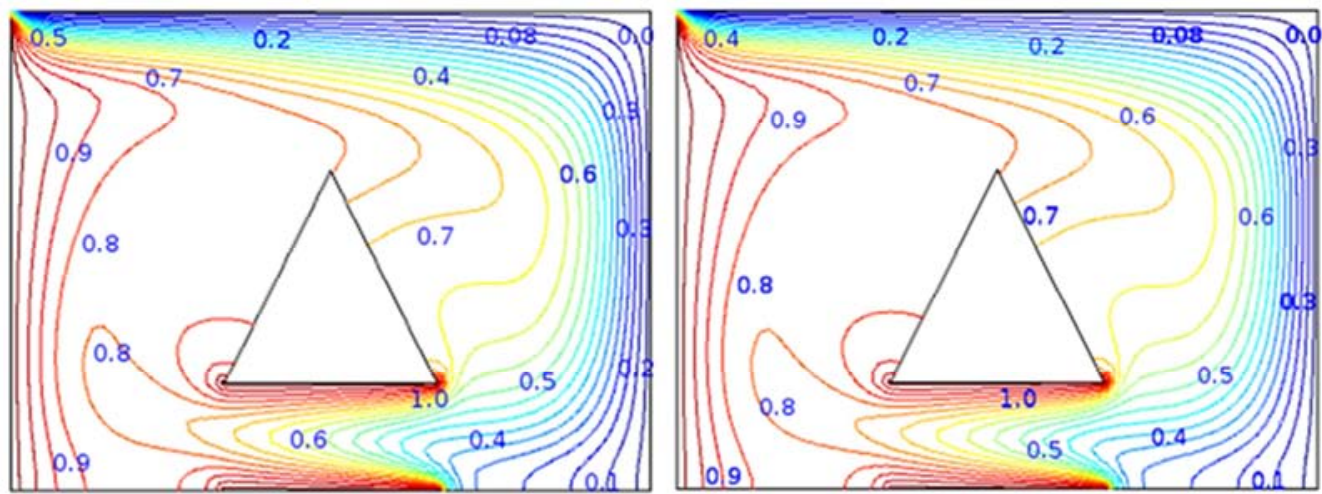

$$
\lambda=0.1
$$

$\lambda=5$
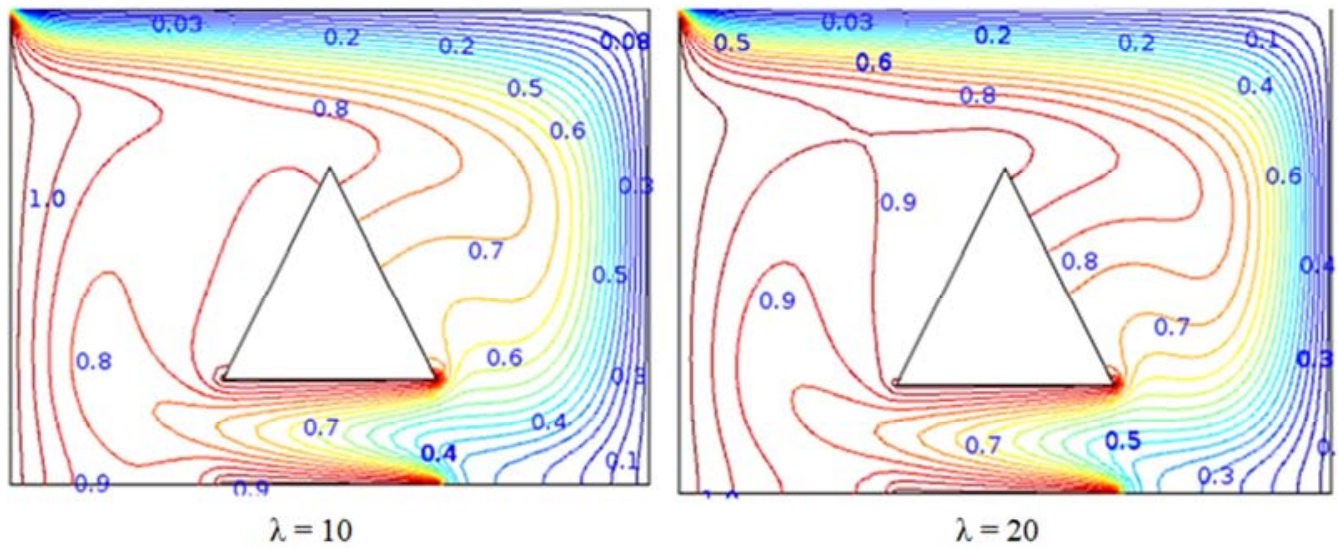

Figure 17. Isotherms for variation of $\lambda=0.1,5,10$ and 20 while, $R a=10^{5}$ and $\operatorname{Pr}=0.71$ 


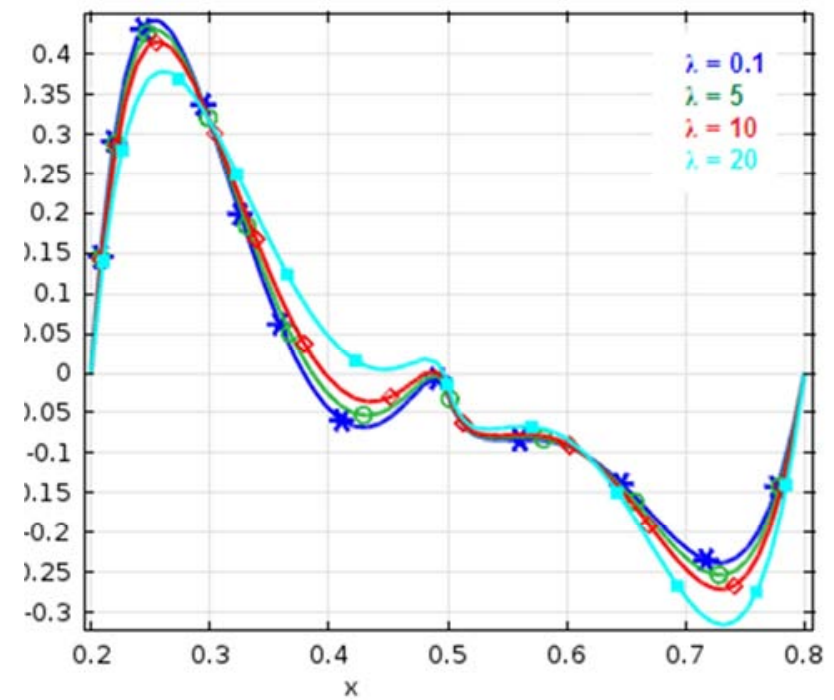

Figure 18. Veliocity graph forR $r=1000$ along the line $y=0.3$.

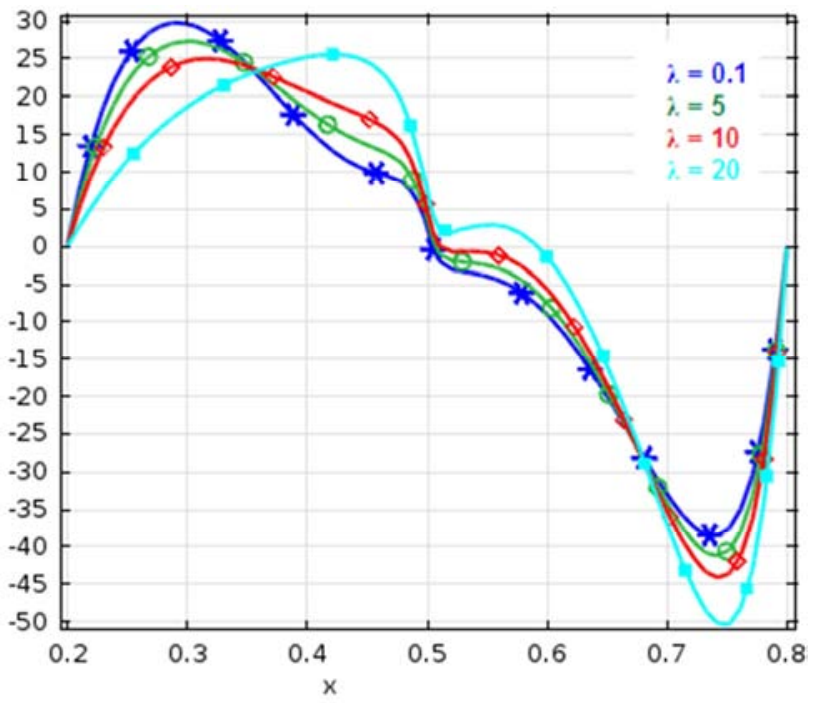

Figure 19. Veliocity graph forR $r=100000$ along the line $y=0.3$.

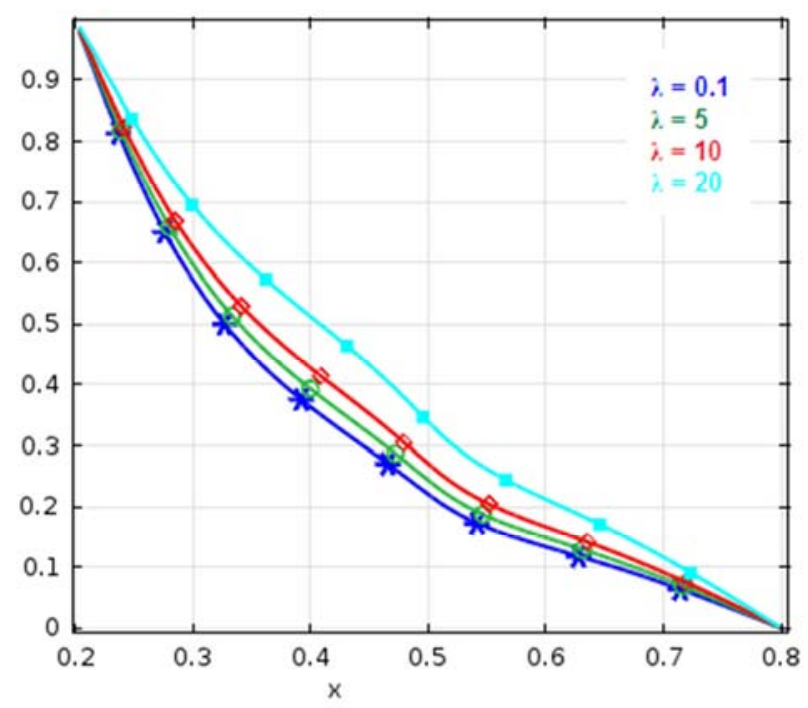

Figure 20. Temperature graph for $R r=1000$ along the line $y=0.3$.

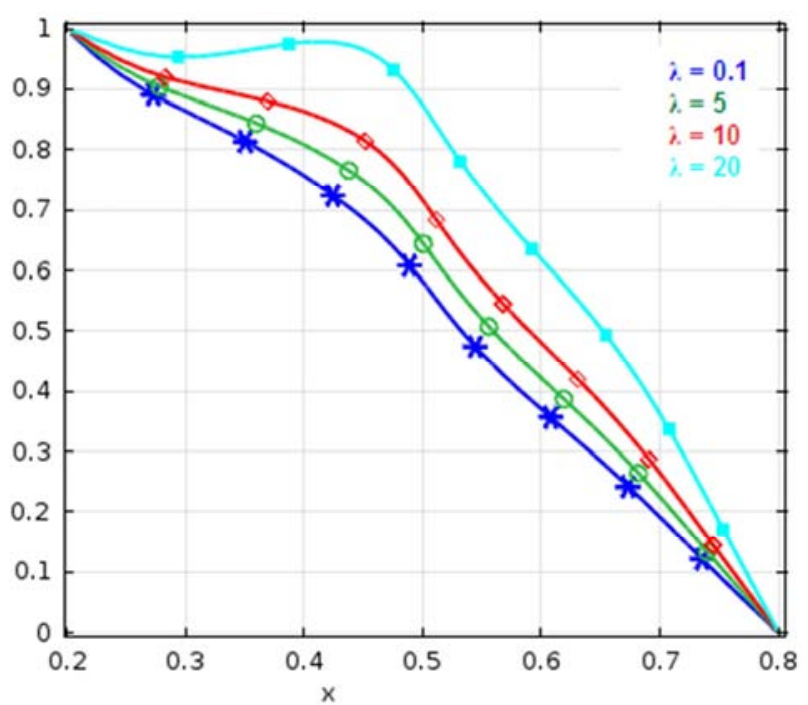

Figure 21. Temperature graph forR $r=100000$ along the line $y=0.3$.

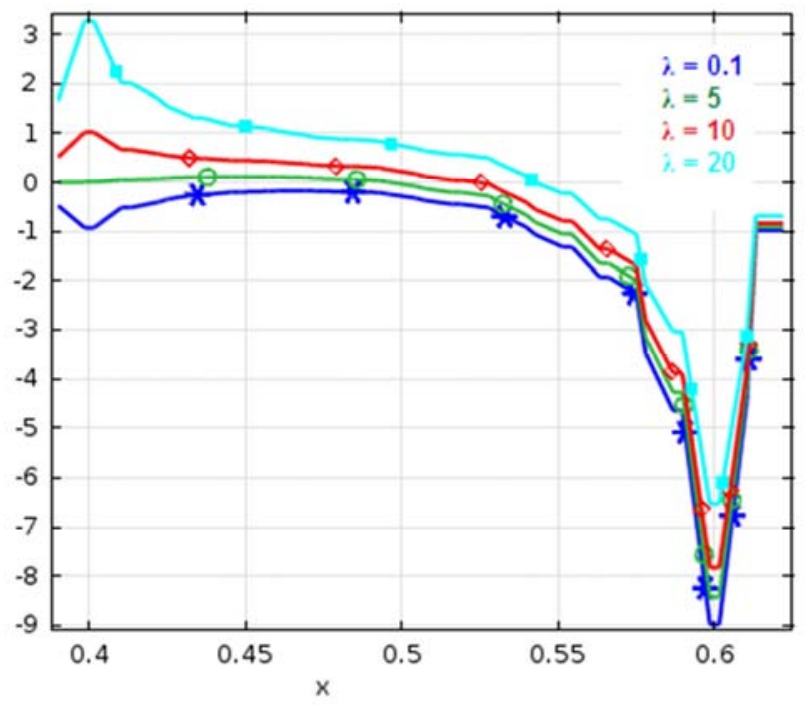

Figure 22. Local Nusselt number forRr $=1000$ along the line the heated line.

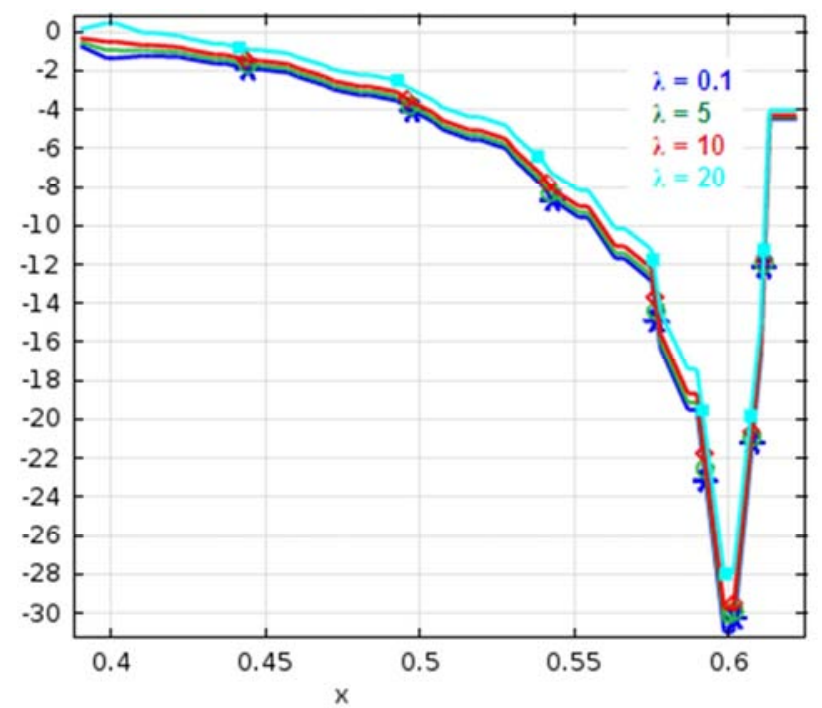

Figure 23. Local Nusselt number forRr $=100000$ along the line the hot line. 


\section{Conclusion}

An investigation for the distribution of streamlines isotherms and local Nusselt number has been carried out to analysis the effect of dimensionless parameter. The study is considered the dimensionless parameter Heat generation, Rayleigh number and Prandtl. The results have been presented for the chosen fluid of Prandtl number $\mathrm{Pr}=$ 0.71 , Rayleigh number $\mathrm{Ra}\left(=10^{3}, 10^{4} 10^{5}\right.$ and $\left.10^{6}\right)$ and heat generation parameter $\lambda(=0.1,5,10$ and 20.0). On the basis of the observation the following conclusion may be drawn:

1. Flow and temperature field are affected by Rayleigh numbers. The average Nusselt number at the hot wall and average fluid temperature in the cavity become higher for the Rayleigh numbers considered.

2. Fluids flow and heat transfer characteristics inside the cavity strongly depend upon the heat generation parameter. The average Nusselt number at the hot wall becomes higher and average fluid temperature in the cavity become higher for the higher values of $\lambda$ considered Rayleigh numbers.

3. The heat generation parameter has significant effect on streamlines and isotherms at the higher values Rayleigh number. The temperature of the fluid in the cavity also increases dueto the increase of the internal heat generation consequently, the rate of heat transfer from hot wall increase.

\section{References}

[1] A. K. Hussein, "Finite Volume Simulation of Natural Convection in a Trapezoidal Cavity Filled with Various Fluids and Heated from the Top Wall" Universal Journal of Fluid Mechanics 1, pp 24-36, 2013.

[2] A. K. Azad, M. J. H. Munshi, M. M Rahman andM. K Chowdhury, "Analysis of Combined Convection in an Open Cavity under Constant Heat Flux Boundary Conditions and Magnetic Field Using Finite Element Method," Journal of scientific research, vol. 6 (2), pp243-256, 2014.

[3] M. Bouabid, N. Hidouri, M. Magherbi, A. Eljery and A. Ben Brahim, "Irreversibility investigation on MHD natural convection in a square cavity for different Prandtl numbers" World Journal of Engineering and physical Sciences Vol. 2 (4), pp. 060-075, 2014.

[4] A. K. Hussein, S. Kumar Rout, F. Fathinia, R. Chand, and M. H. Mohammed, "Natural convection in a triangular top wall enclosure with a solid strip" Journal of Engineering Science and Technology, Vol. 10, No. 10, pp 1326-1341, 2015.

[5] R. Chowdhury, M. A. Hakim Khan, and M. N. A. Alam Siddiki, "Natural Convection in Porous Triangular Enclosure with a Circular Obstacle in Presence of Heat Generation" Vol. 3 (2), pp 51-58, 2015.

[6] S Z. Nejad, and M. M. Keshtkar, "Entropy Generation Analysis of Natural Convection in Square Enclosures with Two Isoflux Heat Source", Engineering Technology \& Applied Science Research Vol. 7, No. 2, Pp1486-1495, 2017.
[7] A. F. Khudheyer, "MHD Mixed Convection in Double LidDriven Differentially Heated Trapezoidal Cavity," International Journal of Application or Innovation in Engineering \& Management Vol. 4, Issue 2, February 2015.

[8] A. Aghaei, A. A. Abbasian Arani and F. Abedi, "Analysis of magnetic field effects on distributed heat sources in a nanofluid-filled enclosure by natural convection," Journal of Applied Fluid Mechanics, Vol. 9, No. 3, pp. 1175-1187, May 2016.

[9] T. Basak, S. Roy and I. Pop, "Heat flow analysis for natural convection within trapezoidal enclosures based on heatline concept," Int. J. Heat Mass Transfer, Vol. 52, Issue 11-12, pp. 2471-2483, May 2009.

[10] S. Jani, M. Mahmoodi, and M. Amini, "Magneto hydrodynamic Free Convection in a Square Cavity Heated from Below and Cooled from Other Walls," International Journal of Mechanical, Aerospace, Industrial, Mechatronic and Manufacturing Engineering, Vol. 7, No. 4, 2013.

[11] M. S. Alam, M. S. H. Mollah, and M. A. Alim, "Finite Element Analysis of Natural Convection in a Rectangular Cavity and Partially Heated Wall", Engineering and Applied Sciences, Vol. 2, No. 3, pp. 53-58, 2017.

[12] M. S. Alam, M. S. Alam, M. A. Alim, and M. S. H. Mollah, "Numerical Simulation of Natural Convection in a Rectangular Cavity with Triangles of Different Orientation in Presence of Magnetic Field," AIP Conference Proceedings 1851, 020037 doi: 10.1063/1.4984666, 2017.

[13] M. S. Alam, M. S. Alam, M. S. H. Mollah, A. H. Bhuiyan and M. A. Alim, "Numerical Simulation of Natural Convection in a Rectangular Cavity with Corner Heater in Presence of Magnetic Field," Journal of Computer and Mathematical Sciences, Vol. 8, No. 6, pp 215-225, June 2017.

[14] M. S. Alam, M. S. Alam, M. S. H. Mollah, and M. A. Alim, "Effect of Prandtl Number on Magneto-Convection in a Lid Driven Square Cavity with a Sinusoidal Vertical Wall", Journal of Multidisciplinary Engineering Science Studies, Vol 3 Issue 8, August-2017Journal of Multidisciplinary Engineering Science Studies, Vol. 3 Issue 8, 2017.

[15] M. S. Alam, M. S. Alam, M. A. Alim, and M. S. H. Mollah "Mixed Magneto Convection in a Lid Driven Square Enclosure with a Sinusoidal Vertical Wall and Joule Heating,", Available online at www.sciencedirect.com1877-7058 (C) 2017 doi 10.1016/j.proeng.2017.08.172, 2017.

[16] A. B. Halim, M. A. Alim and M. U. Nasir "Effect of Hartmann Number on Free Convective Flow in a Square Cavity with Different Positions of Heated Square Block", World Academy of Science, Engineering and Technology International Journal of Mathematical, Computational, Physical, Electrical and Computer Engineering Vol. 8, No. 2, (2014).

[17] M. M. Ali, M. A. Alim and Syed Sabbir Ahmed, Magneto hydrodynamics mixed convection flow in a hexagonal enclosure Procedia Engineering, 194, 479-486 (2017).

[18] M. M. Ali, M. A. Alim, M. A. Maleque, and Syed Sabbir Ahmed, Numerical simulation of MHD free convection flow in a differentially heated square enclosure with tilted obstacle, AIP Conference Proceedings 1851, 020055 (2017); doi: $10.1063 / 1.4984684$. 
[19] Aysharjya Sarkar, M. A. Alim, M. Jahirul Haque Munshi, and M. M. Ali, Numerical study on MHD mixed convection in a lid driven cavity with a wavy top wall and rectangular heaters at the bottom, AIP Conference Proceedings 2121, 030004 (2019) https://doi.org/10.1063/1.5115849.

[20] Md. Imran Hossain, M. A. Maleque, and Mohammad Mokaddes Ali, Numerical study of magneto hydrodynamicmixed convection in a partially heated rectangular enclosure with elliptic block, AIP Conference
Proceedings
2121
030010
(2019); https://doi.org/10.1063/1.5115855.

[21] B. Xu, B. Q. Li and D. E. Stock "An experimental study of thermally induced convection of molten gallium in magnetic fields" International Journal of Heat and Mass Transfer Vol. 49, Pp 2009-2019, 2006. 